\title{
The effects of desflurane and sevoflurane on the intraocular pressure associated with endotracheal intubation in pediatric ophthalmic surgery
}

\author{
Jong Taek Park, Hyun Kyo Lim, Kyu-Yong Jang, and Dea Ja Um \\ Department of Anesthesiology and Pain Medicine, Yonsei University Wonju College of Medicine, Wonju, Korea
}

Background: For ophthalmic surgery anesthesia, it is vital that intraocular pressure (IOP) is controlled. Most anesthetic drugs affect IOP dose-dependently, and inhalational anesthetics dose-dependently decrease IOP. In this study, we compared the effects of desflurane and sevoflurane on IOP and hemodynamics in pediatric ophthalmic surgery.

Methods: Thirty eight pediatric patients from the age of 6 to 15 years, who were scheduled for strabismus surgery and entropion surgery, were randomized to be administered desflurane (group D, n = 19) or sevoflurane (group $S, n=19)$. IOPs and hemodynamic parameters were measured before induction of anesthesia (B), after induction but immediately before intubation (AI), 1 min after intubation (T1), $3 \mathrm{~min}$ after intubation (T3), and 5 min after intubation (T5).

Results: The mean arterial pressure (MAP) at T1 and heart rates (HRs) at T1 and T3 were significantly higher in group D than those in group S. There was no significant difference between the groups in IOP, cardiac index (CI) and stroke index (SI). There was a significant difference within the group in IOP, SI, MAP and HR. There was no significant difference within the group in CI.

Conclusions: There was no significant difference between the groups in IOP and hemodynamic parameters. The two anesthetic agents maintained IOP and hemodynamic parameters in the normal range during anesthetic induction. (Korean J Anesthesiol 2013; 64: 117-121)

Key Words: Desflurane, Intraocular pressure, Sevoflurane.

Received: December 19, 2011. Revised: 1st, March 26, 2012; 2nd, May 15, 2012; 3rd, July 24, 2012. Accepted: July $25,2012$.

Corresponding author: Dea Ja Um, M.D., Department of Anesthesiology and Pain Medicine, Yonsei University Wonju College of Medicine, 162, Ilsan-dong, Wonju 220-701, Korea. Tel: 82-33-741-1536, Fax: 82-33-742-8198, E-mail: umdj@yonsei.ac.kr

(c) This is an open-access article distributed under the terms of the Creative Commons Attribution Non-Commercial License (http:// creativecommons.org/licenses/by-nc/3.0/), which permits unrestricted non-commercial use, distribution, and reproduction in any medium, provided the original work is properly cited. 


\section{Introduction}

Normal intraocular pressure (IOP) is $10-22 \mathrm{mmHg}$ (mean 15 $\mathrm{mmHg}$ ). There can be a $1-2 \mathrm{mmHg}$ change during ventricular contraction, and also a $1-6 \mathrm{mmHg}$ change depending on the body positioning of the patient. IOP is also affected by blood pressure, respiration, coughing, the Valsalva maneuver, blinking, pressure from masks, and endotracheal intubation. For the anesthetic induction of ophthalmic surgery, it is vital that IOP is controlled, because the elevation of IOP can cause the transient loss of vision or acute glaucoma. Most anesthetic drugs affect IOP dose-dependently. Barbiturates, muscle relaxants, opioids, sedatives, etomidate, and propofol can lower the normal IOP and glaucomatic IOP [1].

Park et al. [2] compared the effects of vecuronium and rocuronium on IOP in patients who were intubated. They reported that there was no significant difference between the two groups. The use of desflurane and sevoflurane has been increasing recently. There are some studies comparing the effects of combined sevoflurane and intravenous anesthetics on IOP associated with endotracheal intubation $[3,4]$. There are rare studies comparing the effect of sevoflurane and desflurane, according to the change in cardiovascular parameters. We hoped that the effect of sevoflurane on IOP would be less than that of desflurane, because it has been reported to have a greater modest effect on cardiovascular parameters. Thus, we compared the effects of desflurane and sevoflurane on IOP and changes of cardiovascular parameters associated with endotracheal intubation in pediatric ophthalmic surgery.

\section{Materials and Methods}

We first obtained an approval from the ethics committee of the hospital and a written informed consent from the guardians of the patients. We enrolled 38, American Society of Anesthesiologist physical status classification I and II, pediatric patients of ages between 6 to 15 years who were scheduled for muscle correction of intermittent and right exotropia (strabismus surgery), or the Hotz or sling procedure for entropion (entropion surgery). We placed 19 patients in each group; group $\mathrm{D}$ and group $\mathrm{S}$, in which desflurane and sevoflurane was administered, respectively. The patients were randomly assigned to group $\mathrm{D}$ or group $\mathrm{S}$, using a random number table. We excluded patients from the study if endotracheal intubation had to be attempted two or more times, or if their IOP could not be taken because they were not cooperative before anesthesia induction.

For premedication, we gave all the patients glycopyrrolate 4 $\mu \mathrm{g} / \mathrm{kg}$ and midazolam $0.06 \mathrm{mg} / \mathrm{kg}$, via intramuscular injection 30 min prior to surgery. On arrival, we placed patients in the supine position and allowed them to rest for $5 \mathrm{~min}$. By monitoring the non-invasive blood pressure (NIBP), electrocardiography (ECG) and pulse oximetry, we obtained the mean arterial pressure (MAP), heart rate (HR), and oxygen saturation. Using impedance cardiography (Niccomo ${ }^{\mathrm{TM}}$, Sonosite Medis, Ilenau, Germany), we measured the cardiac index (CI) and stroke index (SI). After dropping 1-2 drops of $0.5 \%$ proparacaine hydrochloride, IOPs were measured, using Tonopen (Tonopen XL, Mentor O\&O, Norwell, Massachusetts, USA) by one ophthalmologist blinded to the anesthetic method; these were determined as the baseline values.

We determined the expiratory volatile anesthetic concentrations using a Raman spectroscopy analyzer (Ohmeda Rascal $^{\mathrm{TM}}$, Ohmeda, Madison, Wisconsin, USA) for desflurane and an infrared gas analyzer (Datex Ultima, Datex Medical Instrumentation, Tewksbury, Massachusetts, USA) for sevoflurane. We administered desflurane with a Dräger vaporizer (Dräger D-vapor, Dräger Medical GmbH, Lübeck, Germany) and sevoflurane with a Dräger vaporizer (Dräger vapor 2000, Dräger Medical GmbH, Lübeck, Germany).

Before surgery, we adjusted the fluid deficit in advance in order to prevent induced hypotension by anesthetics. For preoperative fluid replacement, we considered the weight of the patients and their fasting time. For anesthesia induction, we intravenously administered thiopental sodium $5 \mathrm{mg} / \mathrm{kg}$ after 5 min of preoxygenation with $100 \%$ oxygen. After the loss of verbal response and eyelash reflex, we administered inhalational anesthetics, desflurane (group D) or sevoflurane (group S), via face mask by manual ventilation. Then, we intravenously administered rocuronium bromide $0.8 \mathrm{mg} / \mathrm{kg}$. For adequate muscle relaxation, we manually ventilated the patients for more than 3 min. During this manual ventilation, end-tidal carbon dioxide partial pressure $\left(\mathrm{ETCO}_{2}\right)$ was maintained at 30-35 mmHg. After the expired concentration of inhalational agent reached 1 MAC, we performed endotracheal intubation. During the study, the expired concentration of inhalational agent was kept at 1 MAC.

We recorded and compared the values for IOP, HR, MAP, CI, and SI before induction of anesthesia (B), after induction but immediately before intubation (AI), 1 min after intubation (T1), 3 min after intubation (T3), and 5 min after intubation (T5). All measurements of IOP were performed by one ophthalmologist and all endotracheal intubation was performed by a single anesthesiologist.

Hypotension, defined as a SBP (systolic blood pressure) $\leq 80 \%$ of the baseline SBP, was going to be treated with an intravenous bolus of phenylephrine $1 \mu \mathrm{g} / \mathrm{kg}$ if $\mathrm{HR}>60 \mathrm{bpm}$ or ephedrine $0.1 \mathrm{mg} / \mathrm{kg}$ if $\mathrm{HR}<60 \mathrm{bpm}$. Bradycardia, defined as $\mathrm{HR}<50 \mathrm{bpm}$, was to be treated with an intravenous bolus of atropine $0.01 \mathrm{mg} / \mathrm{kg}$. Pungency and airway irritation during desflurane induction can be manifested by breath-holding, 
coughing and laryngospasm [5,6]. Laryngospasm is a forceful, involuntary spasm of the laryngeal musculature, which caused stimulation of the superior laryngeal nerve, and it was going to be treated with gentle positive-pressure ventilation, an intravenous bolus of lidocaine $1-1.5 \mathrm{mg} / \mathrm{kg}$, or paralysis using intravenous bolus of succinylcholine $0.5-1 \mathrm{mg} / \mathrm{kg}$ [7]. We were going to exclude these cases, which affect the results of this study.

A sample size of nineteen in each group was determined to be appropriate for identifying a $20 \%$ difference with a power of 0.8 , an $\alpha$ value of 0.05 and drop rate of 0.1 for the mean IOP 15.9 $\pm 3.18 \mathrm{mmHg}$, which was determined in ten volunteer patients in a pilot study.

Statistical analyses were performed with PASW Statistics 18 (IBM Corporation, Armonk, New York, USA). All values were shown as the mean $\pm \mathrm{SD}$. We used $\mathrm{X}^{2}$ test to make a sex comparison among the two groups and performed student t-tests for age, weight, height, IOP, MAP, HR, CI, and SI. Repeated Measure Oneway ANOVA was used to compare IOP, MAP, HR, $\mathrm{CI}$, and SI according to each time period by group. $\mathrm{P}<0.05$ was considered statistically significant.

\section{Results}

We excluded six patients (three patients in group D and three patients in group S) because they were not cooperative before anesthesia induction, and their IOPs were not able to be measured. Therefore, we compared and analyzed the dates of thirty two patients (sixteen patients in group D and sixteen patients in group S).

There were no significant differences in patient characteristics between the two groups (Table 1). IOPs at AI, T1, T3, and T5 significantly decreased, compared to IOP at B (P $<0.05)$, but there was no statistical difference between the groups (Table 2). There was no significant difference within the group and between the groups in CI (Table 2). SIs at AI, T1, T3, and T5 significantly decreased, compared to SI at $\mathrm{B}(\mathrm{P}<0.05)$, but there was no significant difference between the groups in SI (Table 2). MAP at T1 significantly increased, compared to MAP at B (P $<0.05$ ), and it was significantly higher in group $\mathrm{D}$ than in group

Table 1. Patients Characteristics

\begin{tabular}{lcc}
\hline & Group D $(\mathrm{n}=16)$ & Group S $(\mathrm{n}=16)$ \\
\hline Sex (M/F) & $8 / 8$ & $12 / 4$ \\
Age (yr) & $9.8 \pm 2.5$ & $9.1 \pm 1.7$ \\
Height (cm) & $143.7 \pm 16.4$ & $137.6 \pm 9.5$ \\
Weight (kg) & $43.2 \pm 13.1$ & $37.5 \pm 8.7$ \\
\hline
\end{tabular}

$\overline{\text { Values are mean } \pm \text { SD or number of patients. } n \text { : number of patients. }}$ Group D: patients with desflurane, Group S: patients with sevoflurane. $\mathrm{P}<0.05$ was considered statistically significant. There were no significant differences between the two groups.
$\mathrm{S}(\mathrm{P}<0.05)$. There was no significant difference between the groups at AI, T3, and T5 in MAP (Table 2). HRs at AI, T1, T3, and T5 significantly increased compared to $\mathrm{HR}$ at $\mathrm{B}(\mathrm{P}<0.05)$. HRs at $\mathrm{T} 1$ and $\mathrm{T} 3$ were significantly higher in group $\mathrm{D}$ than group $\mathrm{S}$, but there was no significant difference between the groups at AI and T5 (Table 2).

In our study, breath-holding, coughing or laryngospasm were not observed during the induction with desflurane. Neither hypotension nor bradycardia was observed during the induction of anesthesia.

\section{Discussion}

Factors affecting IOP are the production rate of aqueous humor, vitreous volume, sclera rigidity, choroidal blood volume, and orbicularis oculi muscle tension [8]. Among these, the

Table 2. Mean Intraocular Pressure and Hemodynamic Parameters

\begin{tabular}{|c|c|c|}
\hline & Group D & Group S \\
\hline \multicolumn{3}{|c|}{ IOP (mmHg) } \\
\hline B & $15.0 \pm 3.6$ & $16.0 \pm 2.5$ \\
\hline AI & $12.0 \pm 3.6^{*}$ & $11.7 \pm 2.0^{*}$ \\
\hline $\mathrm{T} 1$ & $13.5 \pm 3.2^{*}$ & $13.2 \pm 2.4^{*}$ \\
\hline $\mathrm{T} 3$ & $10.8 \pm 3.2^{*}$ & $10.8 \pm 2.5^{*}$ \\
\hline T5 & $9.8 \pm 2.5^{*}$ & $10.1 \pm 2.1^{*}$ \\
\hline \multicolumn{3}{|c|}{$\mathrm{CI}\left(\mathrm{L} / \mathrm{min} / \mathrm{m}^{2}\right)$} \\
\hline B & $2.1 \pm 0.4$ & $2.1 \pm 0.5$ \\
\hline AI & $1.9 \pm 0.3$ & $2.0 \pm 0.5$ \\
\hline $\mathrm{T} 1$ & $2.2 \pm 0.3$ & $2.2 \pm 0.6$ \\
\hline $\mathrm{T} 3$ & $2.2 \pm 0.8$ & $2.1 \pm 0.6$ \\
\hline T5 & $2.2 \pm 0.7$ & $2.0 \pm 0.6$ \\
\hline \multicolumn{3}{|c|}{$\mathrm{SI}\left(\mathrm{ml} / \mathrm{m}^{2}\right)$} \\
\hline B & $36.3 \pm 9.3$ & $37.6 \pm 5.4$ \\
\hline AI & $27.7 \pm 6.1^{*}$ & $31.5 \pm 6.3^{*}$ \\
\hline $\mathrm{T} 1$ & $27.3 \pm 4.7^{*}$ & $28.8 \pm 7.0^{*}$ \\
\hline T3 & $29.6 \pm 6.3^{*}$ & $29.2 \pm 5.9^{*}$ \\
\hline T5 & $30.3 \pm 6.9 *$ & $28.6 \pm 5.6^{*}$ \\
\hline \multicolumn{3}{|c|}{ MAP (mmHg) } \\
\hline B & $85.6 \pm 8.8$ & $80.9 \pm 7.7$ \\
\hline AI & $90.8 \pm 13.9$ & $78.5 \pm 10.8$ \\
\hline $\mathrm{T} 1$ & $102.0 \pm 12.0^{*, \dagger}$ & $98.6 \pm 14.5^{*}$ \\
\hline T3 & $84.8 \pm 11.7$ & $80.2 \pm 7.5$ \\
\hline T5 & $76.2 \pm 9.6$ & $75.0 \pm 6.8$ \\
\hline \multicolumn{3}{|c|}{ HR (beats/min) } \\
\hline B & $91.7 \pm 13.3$ & $83.3 \pm 13.8$ \\
\hline AI & $113.6 \pm 17.9 *$ & $101.2 \pm 16.5^{*}$ \\
\hline $\mathrm{T} 1$ & $127.9 \pm 16.2^{*, \dagger}$ & $117.9 \pm 8.7^{*}$ \\
\hline T3 & $119.1 \pm 15.6^{*, \dagger}$ & $112.4 \pm 7.4^{*}$ \\
\hline T5 & $112.1 \pm 17.7^{*}$ & $109.8 \pm 8.7^{*}$ \\
\hline
\end{tabular}

$\overline{\text { Values are mean } \pm \text { SD. Group D: patients with desflurane, Group }}$ S: patients with sevoflurane. IOP: intraocular pressure, CI: cardiac index, SI: stroke index, MAP: mean arterial pressure, HR: heart rate, $\mathrm{B}$ : before induction of anesthesia, AI: after induction but immediately before intubation, T1: 1 min after intubation, T3: 3 min after intubation, T5: 5 min after intubation. ${ }^{*} \mathrm{P}<0.05$ vs. baseline values (B) within the group. ${ }^{\dagger} \mathrm{P}<0.05$ between the two groups. $\mathrm{P}<0.05$ was considered statistically significant. 
production rate and elimination rate of aqueous humor play the biggest role. In human, the normal range for IOP is 10$22 \mathrm{mmHg}$, and values greater than $24 \mathrm{mmHg}$ are considered pathologic [9]. The baseline IOP values in this study were within this normal range, and none of the patients experienced IOP values of greater than $24 \mathrm{mmHg}$, at any of the five times of measurement. High IOP impairs blood supply to the retina and optic nerve, which lead to a loss of optic nerve function [1]. A patient with a normal IOP can have permanent loss of vision if IOP rises during anesthesia. The acute increase in IOP may be dangerous for patients with impending perforation of the eye, perforating eye injuries, or glaucoma [10]. In addition, the human eye does not appear to have a pressure-sensitive feedback mechanism. Vomiting, coughing, handling of laryngoscope, and tracheal intubation can increase IOP to 30 to $40 \mathrm{mmHg}$ [11]. Therefore, it is important to prevent a significant and sudden increase in IOP, especially, during laryngoscopy and tracheal intubation. Increase in the heart rate and blood pressure are due to reflex sympatho-adrenal discharge provoked by epilaryngeal and laryngotracheal stimulation subsequent to laryngoscopy and tracheal intubation. The IOP rise is secondary to increased sympathetic activity. Adrenergic stimulation can produce an acute increase in IOP, by increasing the resistance to the outflow of aqueous humor in trabecular meshwork between anterior chamber and Schlemn's canal. Some pre-treatments (lignocaine pre-treatment either intravenous or nebulised, or intranasal nitroglycerine) have been used to attenuate ocular and systemic responses to prevent increase in IOP associated with tracheal intubation. Laryngeal mask airway has been proposed as an alternative to endotracheal tube $[10,12,13]$.

Desflurane and sevoflurane have low blood-gas partition coefficients ( 0.42 and 0.65 respectively); as volatile anesthetic agents, they are halogenated that allows for fast anesthesia induction and recovery $[5,14]$. Desflurane causes sympathetic stimulation, and this can lead to transient hypertension and tachycardia [15]. Inhalational anesthetics dose-dependently decrease IOP by suppressing the diencephalon, reducing the production of aqueous humor, raising the outflow of aqueous humor, or relaxing the extraocular muscles. Sevoflurane has several advantages compared with other inhalational anesthetic agents: its low blood and tissue solubility, non-pungency, non-inflammability and limited cardio-respiratory side effects make it the choice for children undergoing general anesthetics $[16,17]$. Cardiovascular parameters during induction of anesthetics with sevoflurane were, on average, quite stable. The most notable difference between the groups is that desflurane group developed a marked increased tachycardia and increase in systolic blood pressure [18]. Cardiovascular stability was achieved with both desflurane and sevoflurane, with MAP and HR maintained within $\pm 20 \%$ of the baseline values during the course of the study. HR and MAP at T1 in this study were significantly higher in group D than in group $\mathrm{S}$. HR at T3 was also significantly higher in group D than in group S. This difference may have been a result of the sympathetic stimulation, associated with the introduction of desflurane after induction of anesthesia with an IV drug [19].

Almeida et al. [20] anesthetized dogs with the two inhalational anesthetics to study the effects on IOP and cardiovascular parameters. They reported that there was no significant difference between the two groups in IOP, HR, MAP, and CVP, but CI was higher in the desflurane group $(\mathrm{P}<0.05)$. In this study, there was also no significant difference in $\mathrm{CI}$ between the two groups.

Nathanson et al. [19] compared the two inhalational anesthetics (desflurane and sevoflurane) in outpatients. They reported that the group induced with desflurane had significantly higher HR compared to the group induced with sevoflurane, which was what the results of the present study also showed.

Jindal et al. [21] compared the two inhalational anesthetics on outpatients and reported that there was no significant difference between the two groups in HR, which differed from the findings of the present study.

Hypercapnia can cause choroidal congestion. Changes in choroidal blood volume can increase IOP rapidly. Decrease in partial pressure of carbon dioxide $\left(\mathrm{pCO}_{2}\right)$ has been associated with both a decrease in choroidal volume and a lower IOP [22]. Hypothermia can decrease IOP [11]. To remove these effects in the present study, $\mathrm{ETCO}_{2}$ was maintained at $30-35 \mathrm{mmHg}$ and normal body temperature was maintained.

The limitations of the present study are as follows: first, during anesthesia induction, the anesthesiologist had to choose one of the two inhalational anesthetics. As such, the two volatile inhalational anesthetics could not be compared using the double-blind method. Second, depth of anesthesia, which also affects IOP, was maintained by adjusting the concentration of the expiratory volatile anesthetic agent with a monitor. Maintaining a stable depth of anesthesia by monitoring BIS (bispectral index system) could have more greatly decreased the effects of depth of anesthesia on IOP. However, BIS monitoring requires sensors to be attached to the forehead, and surgical manipulation can affect the BIS sensor. Therefore, we did not include BIS monitoring in the present study. Third, for anesthesia induction, we intravenously administered thiopental sodium, which could affect IOP and hemodynamic parameters. A gaseous induction of anesthesia can eliminate the effect of thiopental sodium. However, we could not apply inhalational induction, because desflurane is more pungent and is associated with more coughing, breathing-holding, and laryngospasm during an inhalation induction [7].

HR at T1 and T3, and MAP at T1 were significantly higher in group D than in group S. For this reason, we hoped that 
the effect of desflurane on IOP would be more than that of sevoflurane, but there was no statistical difference between the groups. Desflurane and sevoflurane maintained IOP within the normal range during anesthesia induction for pediatric ophthalmic surgery. The cardiovascular parameters were also stable throughout anesthesia induction for both groups. The both anesthetic agents can be used safely in anesthesia induction for pediatric ophthalmic surgery.

\section{References}

1. Feldman MA, Patel A. Anesthesia for eye, ear, nose, and throat surgery. In: Miller's Anesthesia. 7th ed. Edited by Miller RD: Philadelphia, Churchill Livingstone. 2009, pp 2378-83.

2. Park JT, Lee JY, Lee SH, Rah SH, Um DJ. The effects of rocuronium and vecuronium on the increase in intraocular pressure associated with tracheal intubation. Anesth Pain Med 2009; 4: 332-5.

3. Eltzschig HK, Darsow R, Schroeder TH, Hettesheimer H, Guggenberger $\mathrm{H}$. Effect of tracheal intubation or laryngeal mask airway insertion on intraocular pressure using balanced anesthesia with sevoflurane and remifentanil. J Clin Anesth 2001; 13: 264-7.

4. Schäfer R, Klett J, Auffarth G, Polarz H, Völcker HE, Martin E, et al. Intraocular pressure more reduced during anesthesia with propofol than with sevoflurane: both combined with remifentanil. Acta Anaesthesiol Scand 2002; 46: 703-6.

5. Morgan GE Jr, Mikhail MS, Murray MJ. Clinical Anesthesiology. 4th ed. New York, McGraw-Hill. 2006, pp 172-4.

6. Van Hemelrijck J, Smith I, White PF. Use of desflurane for outpatient anesthesia. A comparison with propofol and nitrous oxide. Anesthesiology 1991; 75: 197-203.

7. Morgan GE Jr, Mikhail MS, Murray MJ. Clinical Anesthesiology. 4th ed. New York, McGraw-Hill. 2006, pp 934-9.

8. Cunningham AJ, Barry P. Intraocular pressure-physiology and implications for anaesthetic management. Can Anaesth Soc J 1986; 33: 195-208.

9. Vinik HR. Intraocular pressure changes during rapid sequence induction and intubation: a comparison of rocuronium, atracurium, and succinylcholine. J Clin Anesth 1999; 11: 95-100.

10. Ghai B, Sharma A, Akhtar S. Comparative evaluation of intraocular pressure changes subsequent to insertion of laryngeal mask airway and endotracheal tube. J Postgrad Med 2001; 47: 181-4.

11. McGoldrick KE. Principles of ophthalmic anesthesia. J Clin Anesth 1989; 1: 297-312.

12. Bharti N, Mohanty B, Bithal PK, Dash M, Dash HH. Intra-ocular pressure changes associated with intubation with the intubating laryngeal mask airway compared with conventional laryngoscopy. Anaesth Intensive Care 2008; 36: 431-5.

13. Langham ME, Kitazawa Y, Hart RW. Adrenergic responses in the human eye. J Pharmacol Exp Ther 1971; 179: 47-55.

14. Eberts TJ, Schmid PG. Inhaled anesthetics. In: Clinical Anesthesia. 6th ed. Edited by Barash PG, Gullen BF, Stoelting RK, Cahalan MK, Stock MC: Philadelphia, Lippincott Williams and Wilkins. 2009, pp. 413-43.

15. Ebert TJ, Muzi, M. Sympathetic hyperactivity during desflurane anesthesia in healthy volunteers: a comparison with isoflurane. Anesthesiology 1993; 79: 444-53.

16. Sarner JB, Levine M, Davis PJ, Lerman J, Cook DR, Motoyama EK. Clinical characteristics of sevoflurane in children. A comparison with halothane. Anesthesiology 1995; 82: 38-46.

17. Epstein RH, Mendel HG, Guarnieri KM, Staudt SR, Lessin JB, Marr AT. Sevoflurane versus halothane for general anesthesia in pediatric patients: a comparative study of vital signs, induction, and emergence. J Clin Anesth 1995; 7: 237-44.

18. Yoshitake S, Matsumoto K, Matsumoto S, Uchiumi R, Taniguchi $\mathrm{K}$, Honda N. Effects of sevoflurane and isoflurane on intraocular pressure in adult patients. Masui 1992; 41: 1730-4.

19. Nathanson MH, Fredman B, Smith I, White PF. Sevoflurane versus desflurane for outpatient anesthesia: a comparison of maintenance and recovery profiles. Anesth Analg 1995; 81: 1186-90.

20. Almeida DE, Rezende ML, Nunes N, Laus JL. Evaluation of intraocular pressure in association with cardiovascular parameters in normocapnic dogs anesthetized with sevoflurane and desflurane. Vet Ophthalmol 2004; 7: 265-9.

21. Jindal R, Kumra VP, Narani KK, Sood J. Comparison of maintenance and emergence characteristics after desflurane or sevoflurane in outpatient anaesthesia. Indian J Anaesth 2011; 55: 36-42.

22. Blumberg D, Congdon N, Jampel H, Gilbert D, Elliott R, Rivers R, et al. The effects of sevoflurane and ketamine on intraocular pressure in children during examination under anesthesia. Am J Ophthalmol 2007; 143: 494-9. 